\title{
Cardiothoracic surgery and the National Institutes of Health and National Heart, Lung, and Blood Institute
}

\author{
Damien J. LaPar, MD, and Irving L. Kron, MD
}

Over the past several years, the American Association for Thoracic Surgery (AATS) Council and its Scientific and Government Relations Committee have wrestled with the significant reduction in funding support for cardiothoracic (CT) surgeons from the National Institutes of Health (NIH) and the National Heart, Lung, and Blood Institute (NHLBI). Translational research is the lifeblood of our specialty, and the Council is committed to expanding the specialty's involvement at the national level.

In early August 2010, the NHLBI's Division of Cardiovascular Sciences invited current AATS leadership to present at the Visiting Scholar Lectureship program. This forum afforded an excellent opportunity to share with Dr Susan Shurin, the Acting Director of the NHLBI, and approximately 30 of her professional staff the importance of a special relationship between the field of CT surgery and the NIH and NHLBI.

We present the vital role CT surgery plays in the American Public Health System, the history and contributions the NIH and NHLBI have provided to the advancement of CT surgery, and the unique role CT surgeons play in translational research. We comment on recent trends in $\mathrm{NIH}$ and NHLBI funding success rates of CT surgeons and provide insight into future prospects for $\mathrm{CT}$ research funding.

\section{AMERICAN PUBLIC AND PUBLIC HEALTH SERVICE}

The field of CT surgery significantly benefits the American public and plays a vital role in the American public health system. According to the Centers for Disease Control, cardiovascular and thoracic-related diseases remain the leading causes of death in the United States, with heart disease ranking as number one and lung cancer serving as the principal cause of cancer-related deaths. ${ }^{1}$ Surgical treatment for cardiac and pulmonary disease, therefore, remains of primary importance to the American health system.

In 2008 , more than 207,000 coronary artery bypass grafting $(\mathrm{CABG})$ procedures were performed in the United

\footnotetext{
From the Division of Thoracic and Cardiovascular Surgery, Department of Surgery, University of Virginia School of Medicine, Charlottesville, Va; and The American Association for Thoracic Surgery, Beverly, Mass.

Disclosures: Authors have nothing to disclose with regard to commercial support. Received for publication March 8, 2011; accepted for publication March 21, 2011. Address for reprints: Irving L. Kron, MD, Professor of Surgery, Chairman, Department of Surgery, Division of Thoracic and Cardiovascular Surgery, PO Box 800679, Charlottesville, VA 22908 (E-mail: ilk@ virginia.edu).

J Thorac Cardiovasc Surg 2011;142:20-3

$0022-5223 / \$ 36.00$

Copyright (C) 2011 by The American Association for Thoracic Surgery doi:10.1016/j.jtcvs.2011.03.014
}

States, whereas approximately 102,795 cardiac valve operations and more than 85,000 pulmonary resections were noted within the Agency for Healthcare Research and Quality's Nationwide Inpatient Sample database. ${ }^{2}$ Although it is well known that CABG operative volume has declined in recent times, the volume of cardiac valve operations has remained relatively stable (Figure 1$){ }^{2}$ Nevertheless, CABG still remains one of the most common operations within the United States, and the surgical correction of structural cardiac valve disease is of primary importance to our patients.

CT surgical procedures account for a significant proportion of total US health expenditures. Recent estimates from the American Heart Association and NHLBI indicate that the total costs of cardiovascular disease in the United States for 2009 was $\$ 475.3$ billion. $^{3}$ Furthermore, according to the Agency for Healthcare Research and Quality 2008 national statistics, among a total of 231 principal procedure categories, cardiac procedures alone accounted for 4 of the top 15 procedures with respect to total health expenditures in the United States (Table 1). ${ }^{2}$ These estimates not only highlight the significant burden of CT disease within contemporary surgical practice but also illustrate the relative importance of CT surgical treatment to the American public in current times.

In light of these findings, certain truths emerge. In modern times, CT surgery is common and remains necessary for American patients. In fact, with an increasing elderly population and prevalence of cardiovascular and thoracic disease, an increasing proportion of US patients are likely to require CT surgical procedures. CT surgery consumes a large proportion of total US health expenditures, and this impact is likely to increase in the not too distant future. Consequently, scientifically justified improvements in CT surgical procedures and technology continue to provide great benefit to society.

\section{HISTORY OF CARDIOTHORACIC RESEARCH AND THE ROLE OF THE NATIONAL INSTITUTES OF HEALTH AND NATIONAL HEART, LUNG, AND BLOOD INSTITUTE}

Surgical and CT surgical research have played fundamental roles in the history of American medicine. Further, the role of the surgeon-scientist remains challenging and critical to their success and advancement. As Francis D. Moore, MD, the iconic Peter Bent Brigham Hospital Surgeon-in-Chief, once remarked "the surgical investigator 


\author{
Abbreviations and Acronyms \\ AATS = American Association for Thoracic \\ Surgery \\ $\mathrm{CABG}=$ coronary artery bypass grafting \\ $\mathrm{CT}=$ cardiothoracic \\ NHLBI = National Heart, Lung, and Blood \\ Institute \\ $\mathrm{NIH}=$ National Institutes of Health
}

must be a bridge tender, channeling knowledge from biological science to he patient's bedside and back again. He traces his origins from both ends of the bridge, he is thus a bastard, and everyone calls him this. Those at one end of the bridge say that he is not a very good scientist, and those at the other end say he does not spend enough time in the operating room." This insight underscores the key role that surgical research has played historically and defines the increasing challenges that the modern day surgeon-scientist faces daily.

Historically, CT research has played an integral role in the advancement of medicine and science. Through the pioneering efforts of CT surgical giants, including John H. Gibbon, MD, and C. Walton Lillehei, MD, the development and implementation of contemporary cardiopulmonary bypass technology have transformed the practice of adult and congenital cardiac surgery into a realistic possibility for patients worldwide that, in most cases, is associated with low mortality and significant efficacy. In addition, important advances in myocardial protection, the development and refinement of prosthetic cardiac valves for implantation, and the design and implementation of ventricular assist device technology have transformed CT surgical practice to provide surgeons with a broad armamentarium to combat most functional and structural cardiac disease.

The NIH and NHLBI have played a key role in the advancement of CT surgery research. Whether through the direct intramural support of the development and implantation of the first artificial human mitral valve by Nina Starr Braunwald, MD, in her landmark operation in 1960, the establishment of the National Heart Institute's Clinic of Surgery, or the extramural support of CT research, the importance of the relationship between the academic $\mathrm{CT}$ surgical community and the NIH and NHLBI cannot be emphasized enough. For 37 years (1953-1990), the NIH Surgery Branch along with the National Heart Institute's Clinic of Surgery mentored and trained 170 of today's surgeons, many of whom are academic leaders of contemporary US surgery.

Approximately $30 \%$ of these trainees have achieved the position of Division Chief or Department Chair. Thus, direct NIH support has produced a veritable "Who's Who" of CT surgery during the latter part of the 20th century. The eventual closure of the NIH Clinic of Surgery and the NHLBI cardiac surgery program in 1990 seemed to be a significant step back for the field of CT surgical research. However, in 1990, the acting director of the NHLBI, Claude L'Enfant, MD, addressed many of these concerns with his commitment to the academic CT surgical community: "The decision to close the cardiac surgery program at NHLBI was difficult in that it reduced the opportunity to train academic thoracic surgeons. The emphasis would be shifted towards expanding and creating new programs that would assist the Institute in remaining in the forefront of CT research and allow for the training of surgical investigators." 4 Thus, the dawn of a new horizon for NIH and NHLBI extramural support for the training of new CT surgical investigators seemed eminent. This did not occur. Despite such commitment, there exist only 2 active extramural NIH T32-sponsored CT surgery training grants in the country today.

Extramural NIH and NHLBI support for CT research has proven vital and remains essential to the academic CT surgical community and patients worldwide. The current NHLBI Strategic Plan emphasizes translational research as a vital part of the Institute's mission, and current NIH and NHLBI funding of CT surgery will continue to promote important advances in translational research to enhance patient outcomes and care. Current NHLBI-supported efforts in CT translational research continue to result in important discoveries in the areas of cardiopulmonary bypass, beating heart surgery, cardiac arrhythmia surgery, myocardial protection, heart and lung transplantation, aortic aneurysms, chronic organ rejection, ventricular assist devices, and congenital heart surgery. Despite these advances, however, the success rates for CT surgeons to obtain NIH and NHLBI funding support have declined in recent times, and CT surgeon investigators seem to face an even more difficult set of circumstances in the face of looming economic uncertainty. Complicating the situation even further is the apparent discordance with an increasing need for CT surgical advancement and the declining number of CT surgical applicants to carry forward the academic mission and obligation of our field.

\section{NATIONAL INSTITUTES OF HEALTH SUCCESS RATES FOR CARDIOTHORACIC SURGEONS AND CURRENT FUNDING OPPORTUNITIES}

One of the most alarming realities for the contemporary CT surgical investigator is the increasing difficulty in obtaining NIH extramural support for new and continuing surgical research. In an effort to further understand the driving forces behind such trends, a recent investigation by Ratcliffe and colleagues ${ }^{5}$ addressed the current status of NIH funding for CT surgical research. In their analyses, they determined that although, overall, the number of NIH applications for research funding has dramatically increased in 
A

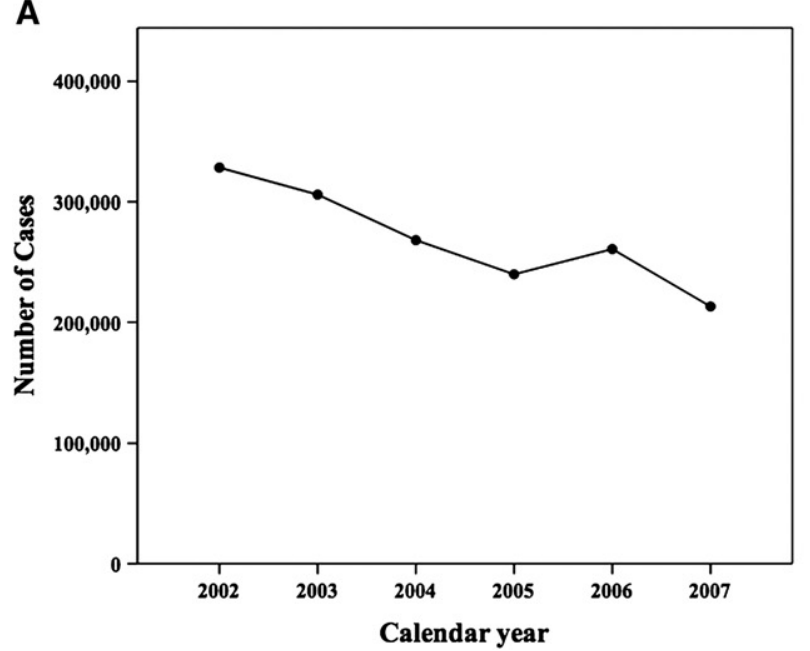

B

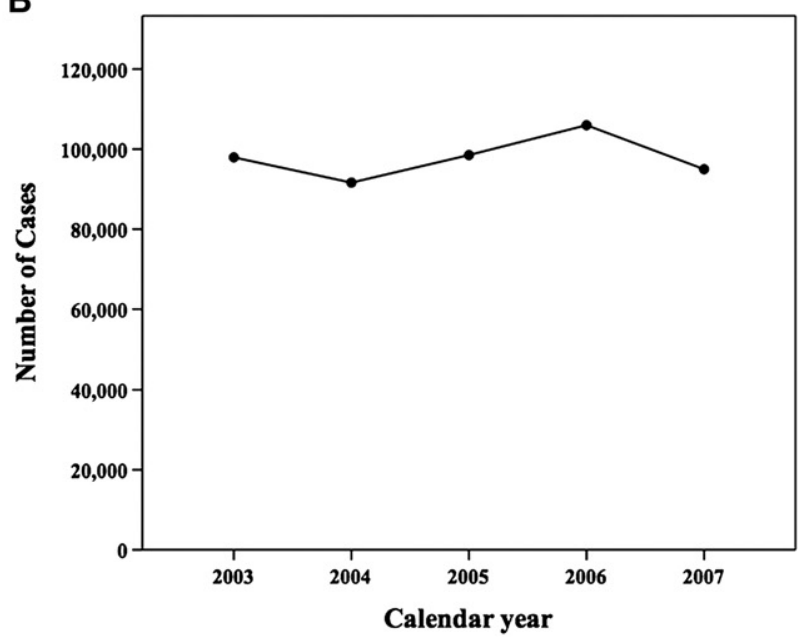

FIGURE 1. A, CABG operative volume within the United States from 2002 to 2007. B, Cardiac valve procedure volume within the United States from 2003 to 2007 .

recent items, the number of NIH awards has remained relatively constant. They noted similar trends for surgical research applications as a whole, as well as among CT surgery as a subspecialty. However, most concerning was their findings that per capita NIH funding of CT surgeons has disproportionately declined since about 2003. They cited the principal reason for this decline being the low per capita number of CT surgery research applications, and they suggested that affirmative action from the NIH favoring funding for CT research may be necessary. In an editorial response to this report, John E. Niederhauser, MD, from the National Cancer Institute, argued against an affirmative action approach and asserted that the responsibility to procure research funding should be that of the leadership of American surgery and the surgeon investigator in concert with institutional and departmental support. ${ }^{6}$ Unfortunately, this approach is not possible.

US academic medical centers and departments do not have the financial resources to support surgeon investigators alone, and the American CT surgical leadership has made

TABLE 1. Mean charges and rank with respect to total health expenditures for cardiothoracic surgery procedures within the United States

\begin{tabular}{lllc}
\hline Principal procedure category* & $\begin{array}{c}\text { Charges } \\
\text { (mean) }\end{array}$ & SEM & Rank $\dagger$ \\
\hline Cardiopulmonary bypass use & $\$ 475,918$ & $\$ 38,303$ & 1 \\
Heart valve procedures & $\$ 161,838$ & $\$ 34,144$ & 6 \\
CABG & $\$ 117,094$ & $\$ 4451$ & 9 \\
Other cardiac procedures & $\$ 42,104$ & $\$ 7284$ & 15 \\
\hline
\end{tabular}

$S E M$, Standard error of the mean; $C A B G$, coronary artery bypass grafting. *Based on Clinical Classifications Software principal procedure categories for International Classification of Disease, 9th Revision, Clinical Modification codes as reported within HCUP Nationwide Inpatient Sample datasets. $\dagger$ Rank number of 231 total possible Clinical Classifications Software categories. significant efforts in recent times to support innovative CT surgical research. Through the joint efforts of the AATS, the Society of Thoracic Surgeons, and the Thoracic Surgery Foundation for Research and Education, several research-based initiatives have been developed and promoted, including multiple research scholarships and fellowships, sponsored courses on research and funding, and awards for outstanding research. However, these opportunities exist through private sponsorship and donations and are insufficient to meet the demands of current and future CT research needs.

\section{FUTURE PROSPECTS FOR CARDIOTHORACIC SURGERY FUNDING}

Despite inherent difficulties, there exist several avenues to improve the future of CT surgery research and funding support. Currently, there are 3 major issues facing the CT surgeon investigator: (1) CT surgery grant applications are not being reviewed by peers; (2) there is a need for increased CT surgery research training programs; and (3) there is a decrease in CT research funding. As a result, some of the NHLBI leadership has expressed their desire to promote a Program Announcement with Review to be established under the auspices of the NHLBI. Although funding through this process would not be allocated specifically for CT research, this process would ensure that NIH and NHLBI grant applications (RO1s) would be reviewed and scored by the NHLBI Review Board. To take full advantage of these opportunities, all grant applications to the NIH Center for Scientific Review should specifically request that CT surgeons sit on the review panel. In addition, the existing NIH-sponsored T24 early stage investigator award may be an avenue that CT surgeon investigators might pursue for additional research training opportunities, and the 
AATS Scientific and Government Relations Committee is currently evaluating methods to expand new research training award mechanisms, similar to those currently used by vascular surgery training program. The NHLBI is currently planning a working group to discuss future directions in cardiac surgery research and the participation of organizations, such as the AATS and Society of Thoracic Surgeons, in developing this initiative. Moreover, there should be more attention focused on multidisciplinary collaboration on clinical trials among CT surgery and other specialties, because this is a primary value of the NHLBI. The CT Surgery Network, sponsored by the NHLBI, is an example of this effort.

\section{CONCLUSIONS}

The issues surrounding the funding difficulties facing contemporary CT surgical investigators are real, complex, and daunting. Although, the NIH and NHLBI have done much to support CT research in the past, it is apparent that the future of $\mathrm{CT}$ research funding remains the responsibility of the academic CT surgical community and the NIH and NHLBI. In response to declining NIH funding success rates in recent times, the American CT surgical leadership has made significant efforts to narrow the gap that exists between required and awarded funding for CT surgical research. The NIH and NHLBI have made some efforts, through the Clinical and Translational Science Award program and the UO1 pathway available from NHLBI Centers for Cardiovascular Outcomes Research. However, as a whole, NIH and NHLBI opportunities are limited at present but show significant promise in the future with continued interaction and collaboration with the NIH and NHLBI. In the end, CT surgery remains critical to the future needs of the American public, and the NIH and NHLBI in partnership with CT leadership have an obligation to promote translational efforts to improve the healthcare of the American public.

\section{References}

1. Centers for Disease Control and Prevention, National Center for Health Statisitics. FastStats. Available at: http://www.cdc.gov/nchs/fastats/deaths.htm. Accessed June 28, 2010

2. Agency for Healthcare Research and Quality. HCUP Nationwide inpatient sample. 2003-2008. Available at: http://www.cdc.gov/nchs/fastats/deaths.htm. Accessed March 8, 2011.

3. American Heart Association. Cardiovascular disease cost. Available at: www. americanheart.org/presenter.jhtml?identifier=4475. Accessed March 8, 2011.

4. Lenfant $C$. The cardiac surgery program of the National Heart, Lung, and Blood Institute. Ann Thorac Surg. 1990;49:1023-4.

5. Ratcliffe MB, Howard C, Mann M, del Nido P. National Institutes of Health funding for cardiothoracic surgical research. J Thorac Cardiovasc Surg. 2008;136 392-9.

6. Niederhuber JE. An old problem that may be getting worse. Ann Surg. 2008;247: 222-3. 